\title{
Evaluating the cooling capacity of diffuse ceiling ventilation system - Full-scale experimental study
}

\author{
Samira Rahnama ${ }^{1,}$, Peter Vilhelm Nielsen ${ }^{2}$, Alireza Afshari ${ }^{1}$, Niels Christian Bergsøe ${ }^{1}$, Hicham Johra ${ }^{2}$, and Rasmus \\ Lund Jensen ${ }^{2}$ \\ ${ }^{1}$ Aalborg University, Danish Building Research Institute, A.C. Meyers Vænge 15, 2450 Copenhagen SV, Denmark \\ ${ }^{2}$ Aalborg University, Department of Civil Engineering, Thomas Manns Vej 23, 9220 Aalborg Ø, Denmark
}

\begin{abstract}
Diffuse ceiling ventilation system is an air distribution system in which part of the suspended ceiling made of perforated panels is used as an air diffuser for the supply of fresh air. This method has been proven to have a higher cooling capacity compared to conventional air distribution systems. The cooling capacity of the system, however, depends on several parameters. This paper presents evaluation results regarding the cooling capacity of the diffuse ceiling ventilation system in connection to two essential parameters, i.e. the distribution of heat sources in the room and the ratio of perforated to non-perforated panels in the ceiling. The evaluation is based on full-scale experiments performed in a laboratory controlled environment and using a design chart which expresses the limits on the supply airflow rate and temperature. The experimental results indicate that the highest cooling capacity is achieved when the heat sources are distributed evenly and the perforated panels cover the entire ceiling. In the case of partial coverage, the cooling capacity is reduced when the heat sources are placed below the perforated panels. The system can have a higher cooling capacity in the partial coverage configuration compared to the full coverage one depending on the supply airflow rate.
\end{abstract}

\section{Introduction}

Diffuse ceiling ventilation systems are air distribution systems in which outdoor air is supplied to the occupied room through the perforated panels installed in the ceiling. In these systems, the whole or part of the ceiling is covered by diffuse panels and outdoor air is distributed in a wide plenum between the diffuse panels and the ceiling slabs. This leads to lower air velocity and allows lower supply air temperature without having thermal discomfort compared to the conventional air distribution systems [1-2]. Thus, diffuse ceiling ventilation systems are able to cope with a higher cooling demand compared to the conventional ones, e.g. mixing or displacement ventilation systems. Nielsen and Jakubowska analysed and compared the cooling capacity of the diffuse ceiling inlet with five other air distribution systems [3]. These experimental results show the ability of diffuse ceiling to handle highest thermal loads compared to all the other systems.

Several parameters influence the cooling capacity of the diffuse ceiling ventilation system. The critical design parameters has been analysed by Zhang et al. [4]. For instance, one important parameter is the geometry of the ventilated room. The cooling capacity is much higher in a room with a lower height. Another parameter is the design of the plenum, i.e. the space above the diffuse panels, where the air is distributed. The objective is having a uniform air distribution in the plenum.
Buoyancy forces generated by heat plume from the heat sources and momentum forces generated by supply air control the airflow pattern in a ventilated space. The buoyancy force is the dominant driven force in diffuse ceiling ventilation systems, due to relatively low supply air velocity that enters the room through the diffuse panels. There are therefore, two essential parameters setting the airflow pattern in the room to consider: the distribution of heat sources in the room and the ratio of perforated to non-perforated panels in the ceiling. The cooling capacity of a diffuse ceiling ventilation system consisting of stone wool elements were tested by Nielsen et al. in a room with the dimension of $6 \mathrm{~m}$ length, $4.65 \mathrm{~m}$ width, $2.5 \mathrm{~m}$ height [5]. Experimental results obtained from testing three different heat sources distribution reveal that evenly distributed heat sources provide a higher cooling capacity than when heat sources are concentrated in one place. Diffuse ceiling ventilation system with three different ratio of perforated to nonperforated panels in the ceiling were tested by Zhang et al. [6]. Experimental results show that the system with partial coverage in the ceiling can develop a higher cooling capacity than systems with diffuse panels covering the whole ceiling. However, heat sources were exactly located below the perforated panels in the experiments with partial coverage. The distribution of heat sources, particularly in relation to diffuse perforated panels in the ceiling, is a key parameter which needs further investigation.

\footnotetext{
* Corresponding author: $\underline{\text { sar@sbi.aau.dk }}$
} 
The current paper presents the analyses results of the cooling capacity of the diffuse ceiling ventilation system via laboratory experiments. The dependence of the cooling capacity on the distribution of heat sources in the room and the ratio of perforated to non-perforated panels in the ceiling is assessed.

\section{Methodologies}

\subsection{Experimental setup}

This study is based on full-scale laboratory experiment. Figure 1 shows the outside and inside view of the so called "Guarded Big Hot Box" test room with the internal dimension of $4.2 \mathrm{~m}$ length, $3.6 \mathrm{~m}$ width and 2.5 $\mathrm{m}$ height [7]. The diffuse ceiling consisted of wood fiber wool cement panels with the dimension of $1.2 \mathrm{~m} \times 0.6$ $\mathrm{m}$. Six electric lamps attached to six cylinders with the height of $1.1 \mathrm{~m}$ were used as heat sources in the room. The input electrical power to the lamps was varied through a regulator in order to have different heat loads in different experimental scenarios.
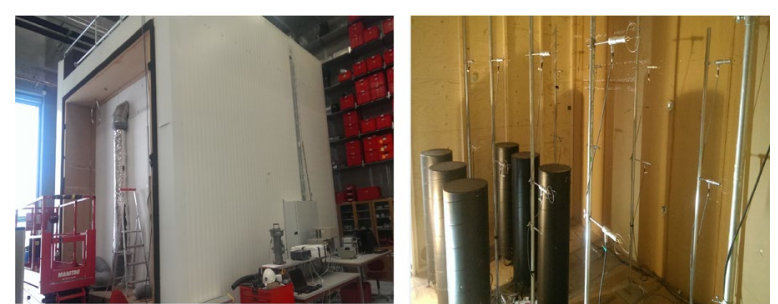

Fig. 1. Outside and inside view of the test room in Aalborg University laboratory, Department of Civil Engineering.

Air velocity and air temperature were measured and logged with Dantec hot-sphere anemometer probes at 45 points in the test room. 15 poles with three anemometers installed on each are placed in the room. The anemometers were located at the heights of $0.1 \mathrm{~m}, 1.1 \mathrm{~m}$ and $1.8 \mathrm{~m}$ on each pole according to DS/EN 15726 standard [8] for measurements in the occupied zone for evaluation of thermal conditions. The accuracy of velocity measurement is $\pm 0.02 \mathrm{~m} / \mathrm{s}$ for the range of $0-1$ $\mathrm{m} / \mathrm{s}$ [9]. Figure 2 shows the placement of the poles on the floor. The poles were placed with $0.5 \mathrm{~m}$ distance from the walls in order to cover the occupied zone based on recommendations from DS/EN 13779 [10].

The ventilation supply airflow rate to the room was controlled by a frequency transformer connected to the supply fan. The former was measured with an orifice plate and a pressure difference transducer. Supply and exhaust airflow rate were adjusted so that the pressure difference between the room and the laboratory space was close to zero. Supply and exhaust air temperature were measured with type-k thermocouples placed inside the supply and exhaust air ducts and were logged with a Fluke Helios 2287 data logger. The uncertainty of the temperature instrument is $\pm 0.15 \mathrm{~K}$ [11]. Temperatures inside the guarded thermal zones surrounding the test room were measured in several locations.

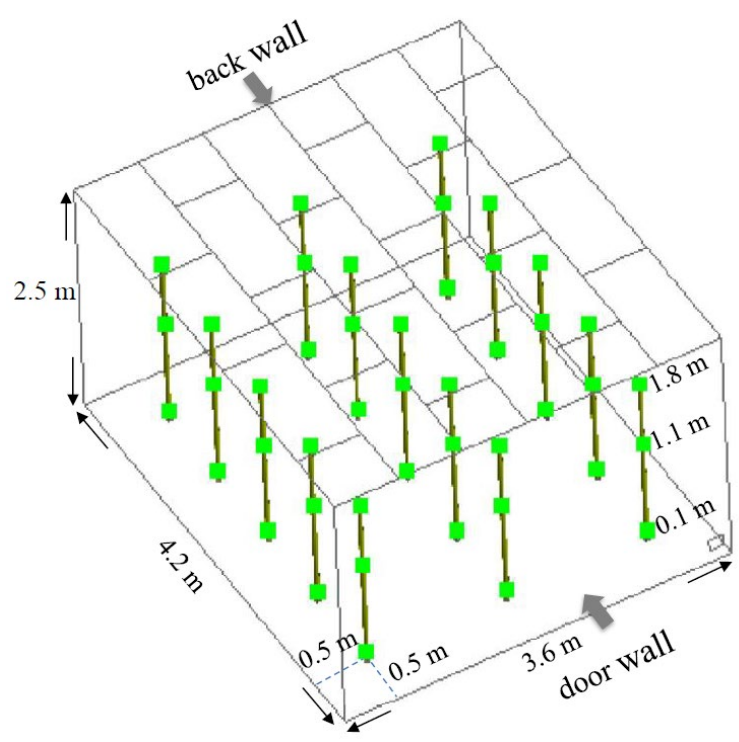

Fig. 2. Location of poles on the floor and location of anemometer probes on each pole

\subsection{Experimental scenarios}

Four scenarios, illustrated in Figure 3, with different distribution of heat sources and ratios of perforated to non-perforated panels in the ceiling were tested. Scenario 1 is with $100 \%$ perforated diffuse panels and evenly distributed heat sources. Scenario 2 is with $100 \%$ perforated diffuse panels and the heat sources concentrated close to the back wall. Scenario 3 is with $2.4 \%$ perforated diffuse panels and the heat sources concentrated close to the back wall. Scenario 4 is with $2.4 \%$ perforated diffuse panels and heat sources close to the door wall, below the perforated panel.

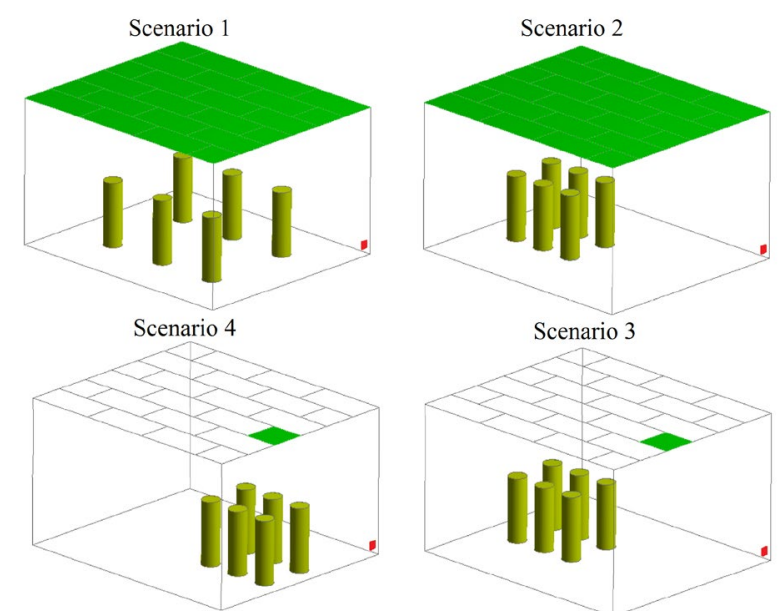

Fig. 3. Four experimental scenarios with different distribution of heat sources and different ratios of perforated to nonperforated panels in the ceiling- supply and exhaust areas are highlighted in green and red on the ceiling and the door wall respectively

Two sets of experiment were conducted in Scenario 1 and Scenario 4. In one set, the heat sources were first turned on in the initial step. The ventilation system was 
kept off for several minutes to allow the development of buoyancy-driven airflow from the heat sources in the room. Then, the ventilation system was swtiched on. In the other set of experiments, the ventilation system was in operation when the heat sources were turned on, allowing the momentum-driven airflow to first develop in the room. The purpose of these experiments was to study the interaction between the two airflows and the effect of that on the airflow pattern in the room. Considering the above-mentioned scenarios, the followings have been investigated:

- The influence of heat sources distribution on the cooling capacity when the diffuse panels cover the entire ceiling (Comparison of Scenario 1 and Scenario 2)

- The influence of heat sources distribution on the cooling capacity when the diffuse panels cover part of the ceiling (Comparison of Scenario 3 and Scenario 4)

- The influence of different ratios of perforated to nonperforated panels on the cooling capacity for the same heat sources distribution (Comparison of Scenario 2 and Scenario 3)

- The influence of different initial situations, whether the ventilation system starts operation before the heat sources or vice versa

\subsection{Design chart}

A design chart method has been developed by Nielsen [12], which makes it possible to compare different air distribution systems in a certain situation. The design chart is a $q_{0^{-}} \Delta T_{0}$ chart, where $q_{0}\left[\mathrm{~m}^{3} / \mathrm{s}\right]$ is the supply airflow rate and $\Delta T_{0}\left[{ }^{\circ} \mathrm{C}\right]$ is the temperature difference between the supply and exhaust air. The idea is to find the limits on the supply airflow rate, and the temperature difference of the supply and exhaust air while an acceptable comfort level is satisfied. There are upper and lower limits on $q_{0}$ and $\Delta T_{0}$ due to limits on draft, room temperature gradient, indoor air quality, cooling capacity, the design of the duct system, etc. The focus in this study is on evaluating the cooling capacity of the system represented as the product of $q_{0}$ and $\Delta T_{0}$ :

$$
Q=\rho c_{\mathrm{p}} q_{0} \Delta T_{0}
$$

Where, $Q[\mathrm{~W}]$ is the cooling capacity, i.e. the heat load that can be removed by an air distribution system, $c_{\mathrm{p}}$ $\left[\mathrm{J} / \mathrm{kg} .{ }^{\circ} \mathrm{C}\right]$ is the specific heat capacity and $\rho\left[\mathrm{kg} / \mathrm{m}^{3}\right]$ is the density of air. The objective is to compare the cooling capacity of the system in connection with the heat sources distribution in the room and the ratios of perforated diffuse panels to non-perforated panels in the ceiling. To make comparison, the cooling capacity has been calculated when the maximum air velocity in the room is limited to a certain value. The air velocity in the room is a parameter which affects the thermal comfort. The design charts can be based on any acceptable maximum air velocity. Similar to the previous works, the maximum velocity of $15 \mathrm{~cm} / \mathrm{s}$ is considered in this paper. In order to obtain points on the design chart, the laboratory experiments were conducted as follows: The measurements during a steady state period of three hours were used, when the supply airflow rate, supply air temperature and supply power to the heat sources were adjusted to certain values and the room temperature was stable. The air velocities were logged every 0.2 seconds at the locations shown in Figure 2. Running average velocities over 3 minutes (according to DS/EN 13182 [13]) are calculated for each anemometer probes during the three hours of the test. The maximum value for each measuring probe is selected, among the samples which covers the $97 \%$ of entire period. This provides 45 samples corresponding to 45 measuring probes, of which, the maximum value is considered to evaluate the air velocity in the room. This velocity can be considered for the point with the adjusted heat load, supply airflow rate and supply air temperature. However, an additional calculation is required in order to be able to compare the different cases.

It is desired to have a fixed and known heat load during the steady-state measurement periods. In order to prevent heat flux between the test room and the surrounding environment, the room temperature should be kept equal to the surrounding guarded zone temperature. In this situation, the heat load is equal to the adjusted heat load of the heat sources. However, in practice, a temperature difference between the test room and the surrounding environment is inevitable. This has been addressed by recalculating $\Delta T_{0}$ based on the measured $Q$ and $q_{0}$ using Eq. (1), rather than using the measured $\Delta T_{0}$ in obtaining the points on the design chart. The points with the recalculated $\Delta T_{0}$ are the points in which the heat flow in the room is only generated by the heat sources. The momentum flow arising from the heat flow through the envelope is small compared to the momentum flow from the heat sources due to rather small temperature difference between the test room and the surrounding environment during the experiments. Thus, the influence of heat flow through the envelope on the air velocity in the room is assumed to be negligible.

\section{Results and discussion}

The experiments were performed at three different ventilation inlet airflow rates equal to $40 \mathrm{l} / \mathrm{s}, 80 \mathrm{l} / \mathrm{s}$ and $100 \mathrm{l} / \mathrm{s}$ providing three points on the design chart for each scenario. In practice, it is unlikely to run experiments which yields the air velocity exactly equals to $15 \mathrm{~cm} / \mathrm{s}$. One can run several experiments and use interpolation techniques to obtain the point with a certain velocity. In this paper, at least two experiments were performed at each above-mentioned airflow rate. In these experiments, either the heat load or the supply temperature were set differently. Then, linear interpolation and/or extrapolation were applied to find the points with the desired air velocity.

Figure 4 shows the design graph for Scenario 1 and Scenario 2 to see the influence of heat sources distribution in the $100 \%$ ratio of perforated to nonperforated panels in the ceiling. The points with $15 \mathrm{~cm} / \mathrm{s}$ velocity are connected through straight lines to form the constant velocity curves. The results indicate the higher cooling capacity of the system in Scenario 1 compared to Scenario 2. The system with evenly distributed heat 
sources is able to remove a higher heat load than the system with heat sources concentrated to one corner at the same thermal condition, i.e. the air velocity of 15 $\mathrm{cm} / \mathrm{s}$ and the average room air temperature equal to the surrounding environment temperature. The laboratory temperature variations were not considerable (between $21{ }^{\circ} \mathrm{C}$ to $23^{\circ} \mathrm{C}$ ) during the measurements in all scenarios and the laboratory temperature can be assumed constant. Similar results are obtained in [5] for the same experiment, but in a larger room and with a different ceiling material.

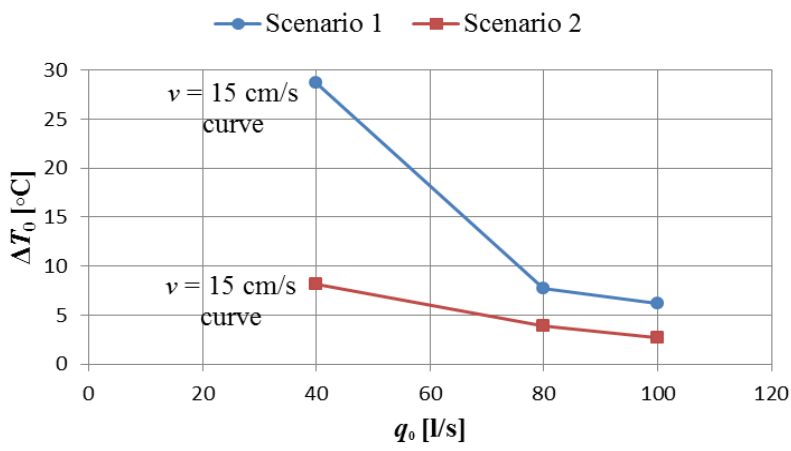

Fig. 4. Design graph showing the constant velocity curves of $15 \mathrm{~cm} / \mathrm{s}$ for Scenario $1(100 \%$ diffuse ceiling and evenly distributed heat sources) and Scenario 2 (100\% diffuse ceiling and the heat sources concentrated close to the back wall)

Figure 5 shows the design graph for Scenario 2 and Scenario 3 to see the influence of different ratios of perforated to non-perforated panels in the ceiling in the same heat sources distribution. The constant velocity curve of $15 \mathrm{~cm} / \mathrm{s}$ is shown for Scenario 2. For Scenario 3 , a point with $15 \mathrm{~cm} / \mathrm{s}$ is obtained at the supply airflow rate of $40 \mathrm{l} / \mathrm{s}$. However, as the supply airflow rate increased during the experiment, the air velocity in the room increased rapidly. Practically, it was not possible to reach a point with the air velocity of $15 \mathrm{~cm} / \mathrm{s}$ at the supply air flow rates higher than $40 \mathrm{l} / \mathrm{s}$ with the available experimental setup. To understand the increasing rate of air velocity in the room, the constant heat load curve of $470 \mathrm{~W}$ is shown for Scenario 3. The curve has a hyperbolic form which indicates the constant value for the product of $q_{0}$ and $\Delta T_{0}$ representing the heat load. As shown, the air velocity is considerably higher in higher supply airflow rates in order to remove the same heat load. This translates to considerably lower cooling capacities in higher supply airflow rates for providing the same thermal comfort.

The results show that the system with $2.4 \%$ diffuse panel ratio in Scenario 3 has a higher cooling capacity than the system with $100 \%$ diffuse panel ratio at the supply airflow rate of $40 \mathrm{l} / \mathrm{s}$. This is consistent with the earlier results obtained Zhang et al. [6]. There, the system with $18 \%$ diffuse panel is showing a higher cooling capacity than the system with $100 \%$ diffuse panel, where the heat sources were exactly located below the diffuse panels in the experiments with $18 \%$ diffuse panel. Here, the same result can be seen at the supply airflow rate of $40 \mathrm{l} / \mathrm{s}$, even though the heat sources were located far from the diffuse panels in Scenario 3. In the small diffuse panel ratio of $2.4 \%$, the ventilation system is similar to a mixing ventilation system and mainly momentum-driven, especially in the higher airflow rates. Thus, the curve is expected to fall down, i.e. the cooling capacity decreases to zero rapidly, similar to the mixing ventilation graph shown in [12]. In fact, the areas close to the diffuse panel in Scenario 3 and Scenario 4 is outside the occupied zone, due to rather high air velocity in these areas. Thus, the air velocities measured just below the diffuse panel are not taken into account when calculating the maximum air velocity in Scenario 3 and Scenario 4.

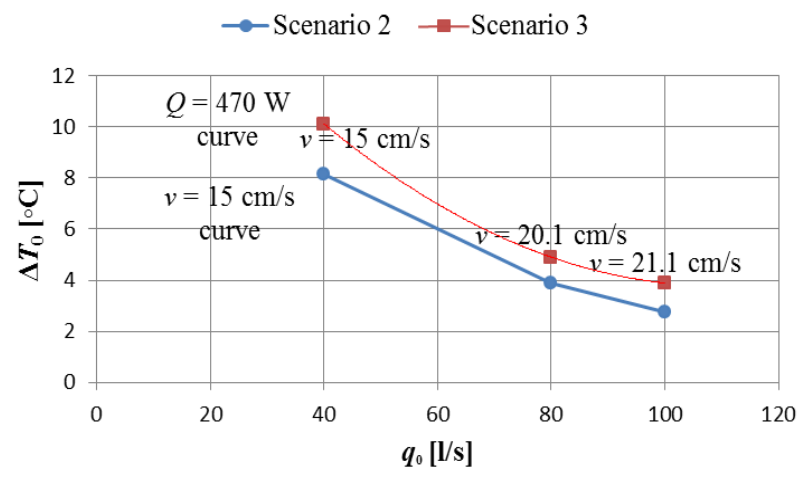

Fig. 5. Design graph showing the constant velocity curve of $15 \mathrm{~cm} / \mathrm{s}$ for Scenario $2(100 \%$ diffuse ceiling and the heat sources concentrated close to the back wall) and the constant heat load curve of $470 \mathrm{~W}$ for Scenario 3 (2.4\% diffuse ceiling and the heat sources concentrated close to the back wall)

Figure 6 shows the design graph for Scenario 3 and Scenario 4 to see the influence of heat sources distribution in the $2.4 \%$ ratio of diffuse panel in the ceiling. Again, due to practical limitations, it was not possible to measure the points with the air velocity close to $15 \mathrm{~cm} / \mathrm{s}$ for these scenarios. Thus, an accurate interpolation is not possible in order to provide the constant velocity curves of $15 \mathrm{~cm} / \mathrm{s}$. Instead, the constant heat load curve of $470 \mathrm{~W}$ is shown together with the air velocity correspond to each point for each scenario. The air velocities are higher in Scenario 4 than in Scenario 3 in order to remove the same heat load. This indicates the higher cooling capacity of the system in Scenario 3 than in Scenario 4 at the same thermal comfort condition. The cooling capacity reduces when the heat sources are placed below the diffuse panel while the major part of the ceiling is made of non-perforated panels.

Figure 7 shows the design graph for Scenario 1 in the two sets of experiments explained in Section 2.2, to see the influence of different initial situations, whether the ventilation system starts operation before the heat sources or vice versa. The constant velocity curves of $15 \mathrm{~cm} / \mathrm{s}$ are shown. The experimental results indicate that the influence is insignificant for the supply airflow rate of $80 \mathrm{l} / \mathrm{s}$ and $100 \mathrm{l} / \mathrm{s}$. However, the cooling capacity is higher when the heat sources started operation first for the supply airflow rate of $40 \mathrm{l} / \mathrm{s}$. To illustrate the differences, the velocity contours for the two sets of experiment on the surfaces $0.1 \mathrm{~m}$ above the floor are 
shown in Figure 8. The contour plots are made based on the air velocity measurements at 15 points at the supply airflow rate of $40 \mathrm{l} / \mathrm{s}$. As can be seen, the difference between the air velocities in the entire surface is insignificant for the two experiments. The maximum air velocity occurred at the same place in both experiments, but with a difference of around $1 \mathrm{~cm} / \mathrm{s}$. This difference is insignificant and can be explained by the uncertainty of the anemometer probe measurements. Likewise, the same results were obtained for the two set of experiments tested in Scenario 4.

- Scenario $3 \times$ Scenario 4

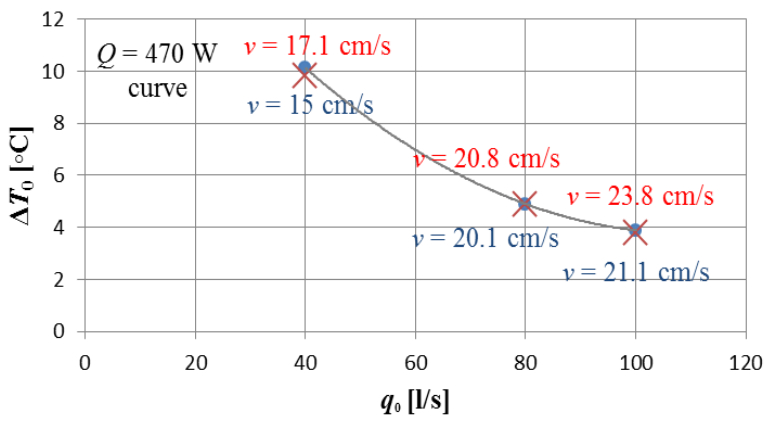

Fig. 6. Design graph showing the constant heat load curves of $470 \mathrm{~W}$ for Scenario 3 (2.4\% diffuse ceiling and the heat sources concentrated close to the back wall) and Scenario 4 ( $2.4 \%$ diffuse ceiling and the heat sources concentrated close to the door wall)

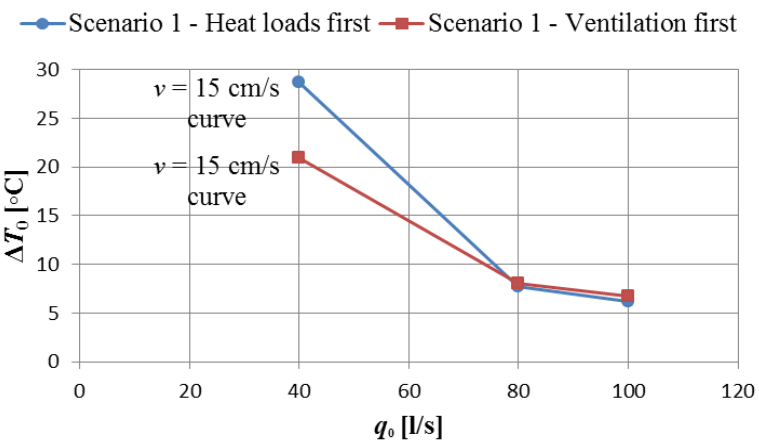

Fig. 7. Design graph showing the constant velocity curves of $15 \mathrm{~cm} / \mathrm{s}$ for Scenario $1(100 \%$ diffuse ceiling and evenly distributed heat sources) in two sets of experiments, where in one heat sources and in the other ventilation system started first.

\section{Conclusion and future work}

This paper evaluates experimentally the cooling capacity of the diffuse ceiling ventilation system and its dependency to the relative location of heat sources in the room and the diffuse panel area in the ceiling. Several scenarios were tested in a test room with the diffuse ceiling and the dimension of $4.2 \times 3.6 \times 2.5 \mathrm{~m}(\mathrm{~L} \times \mathrm{W} \times \mathrm{H})$. The different scenarios were compared through a design chart showing the limits on the supply airflow rate and the temperature difference between supply and exhaust air in order to have either a constant air velocity in the room or a constant heat load removed from the room.
Two different diffuse panel ratios in the ceiling, i.e. $100 \%$ and $2.4 \%$ diffuse ceiling, were considered. In the case of $100 \%$ diffuse ceiling, the cooling capacity was higher when the heat sources were distributed evenly in the room. In the case of $2.4 \%$ diffuse ceiling, the cooling capacity reduced when the heat sources were exactly placed below the inlet diffuse ceiling. Comparing the systems with the same heat sources distribution in the two different diffuse panel ratios revealed that a higher cooling capacity is possible for a smaller diffuse panel ratio. The system with $2.4 \%$ diffuse ceiling had a higher cooling capacity compared to the $100 \%$ diffuse ceiling in the rather low supply airflow rate of $40 \mathrm{l} / \mathrm{s}$. However, the cooling capacity reduced rapidly in the small ratio of diffuse panel with the increase of the supply airflow. In fact, the system was rather a mixing ventilation system than a diffuse ceiling ventilation system in the small ratio of perforated to non-perforated panels. In addition, several experiments were run to see the influence of different start-up operations, i.e. whether the heat sources or the ventilation starts operation first. The results showed an insignificant effect of different startup operations on the cooling capacity.
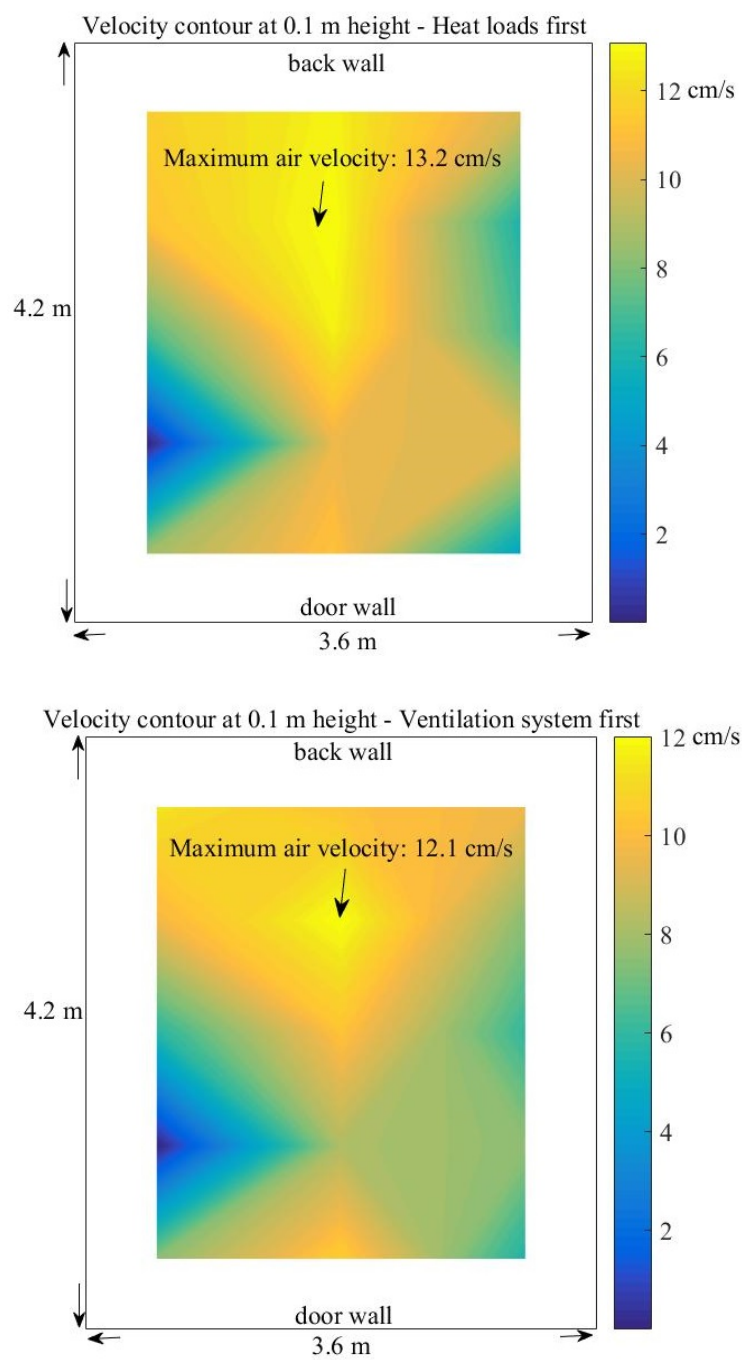

Fig. 8. Air velocity contours at the surfaces $0.1 \mathrm{~m}$ above the floor for the experiment with heat sources started operation 
first (top plot) and the experiment with ventilation system started operation first (bottom plot) at the supply airflow rate of $40 \mathrm{l} / \mathrm{s}$.

The diffuse ceiling ventilation system was tested experimentally in a limited number of scenarios due to practical limitations. Future plan is to investigate more scenarios with CFD simulation, where the experimental results can be used to validate the CFD model.

\section{Acknowledgement}

This work is carried out as a collaboration between The Danish Building Research Institute at Aalborg University Copenhagen and Troldtekt A/S. The project is financially supported by ELFORSK, a research and development program administrated by Danish Energy.

\section{References}

1. J. Fan, C.A. Hvidd, H. Yang, Performance analysis of a new design of office diffuse ceiling ventilation system, Energy and Buildings 59, 73-81 (2013)

2. P. Jacobs, E.C.M. Van Oeffelen, B. Knoll, Diffuse ceiling ventilation, a new concept for healthy and productive classrooms, Indoor Air, Copenhagen, Denmark (2008)

3. P.V. Nielsen, E. Jakubowska, The performance of diffuse ceiling inlet and other room air distribution systems, Cold climate HVAC (2009)

4. C. Zhang, T. Yu, P.K. Heiselberg, M.Z. Pomianowski, P.V. Nielsen, Diffuse ceiling ventilation: design guide, Technical report, Aalborg University, Department of Civil Engineering. No. 217 (2016)

5. P.V. Nielsen, R.W. Vilsbøll, L. Liu, R.L. Jensen, Diffuse Ceiling Ventilation and the Influence of Room Height and Heat Load Distribution, Healthy Building, Eindhoven, Netherland (2015)

6. C. Zhang, M.H. Kristensen, J.S. Jensen, P.K. Heiselberg, R.L. Jensen, M. Pomianowski, Parametrical analysis on the diffuse ceiling ventilation by experimental and numerical studies, Energy and Building, vol. 111, pp. 87-97 (2016)

7. C. Zhang, P.K. Heiselberg, M. Pomianowski, T. Yu, Experimental study of diffuse ceiling ventilation coupled with a thermally activated building construction in an office room, Energy and Building, vol. 105, pp. 60-70 (2015)

8. DS/EN 15726 Dansk standard, Ventilation for buildings - Air diffusion - Measurements in the occupied zone of air conditioned/ventilated rooms to evaluate thermal and acoustic conditions (2012)

9. M. H. Kristensen, J. S. Jensen, R. L. Jensen, Air temperature measurements using Dantec Draught Probes, Aalborg: Department of Civil Engineering, Aalborg University. DCE Technical reports, No 189 (2015).
10. DS/EN 13779 Dansk standard, Ventilation for nonresidential buildings - Performance requirements for ventilation and room-conditioning systems (2007)

11. J. L. Dreau, P. Heiselberg, R. L. Jensen, Experimental data from a full-scale facility investigating radiant and convective terminals: Uncertainty and sensitivity analysis, Description of the experimental data. Aalborg: Department of Civil Engineering, Aalborg University. DCE Technical reports, No. 168 (2014)

12. P.V. Nielsen, Analysis and design of room air distribution systems, HVAC\&R Research, 13:6, 987-997 (2007)

13. DS/EN 13182 Dansk standard, Ventilation For Buildings - Instrumentation Requirements For Air Velocity Measurements In Ventilated Spaces (2002) 